\section{Summary of: Practitioners' perspectives and experiences of the new National Health Service dental contract}

\author{
I. G. Chestnutt, ${ }^{1}$ L. Davies² and D. R. Thomas ${ }^{3}$
}

VERIFIABLE CPD PAPER

\section{FULL PAPER DETAILS}

1"Professor and Honorary Consultant in Public Dental Health, ${ }^{2}$ Research Associate, Dental Public Health Unit, Cardiff University Dental School, Heath Park, Cardiff, CF14 4XY; ${ }^{3}$ Consultant in Dental Public Health, National Public Health Service for Wales, Mamhilad House, Mamhilad Park Estate, Pontypool, NP4 OYP

${ }^{*}$ Correspondence to: Professor Ivor G. Chestnutt

Tel: +44 (0)29 2074 6680;

Fax: +44 (0)292074 6489 Email: chestnuttig@ cardiff.ac.uk

Online article number E18

Refereed Paper - accepted 28 November 2008

DOI: $10.1038 /$ sj.bdj.2009.354

${ }^{\circ}$ British Dental Journal 2009; 206: E18

\begin{abstract}
Background In April 2006, fundamental changes were made to the arrangements for commissioning state funded (National Health Service, NHS) dental care in England and Wales. These involved the dissolution of a universal national contract and the introduction of locally commissioned primary dental care services. Suggested advantages included the elimination of a fee-for-item 'treadmill', an increased emphasis on prevention and improved patient access. This change came at a time when many practitioners were opting to provide care outside the NHS. Objectives This study investigated dentists' experience of the new contract and compared this with attitudes determined in a previous survey of the same cohort of dentists conducted immediately before the changed commissioning arrangements. Methods Data were collected via a postal questionnaire, comprising a combination of 60 open and closed questions, mailed to 608 general dental practitioners in Wales. Results Four hundred and ninety-six (77\%) questionnaires were returned. Four hundred and seventeen practitioners continued to provide NHS dental care. Only $46(11 \%)$ of the 417 practitioners agreed that they liked the new method of remuneration and the majority (362 [86.8\%]) perceived that they still delivered state-funded care in a 'treadmill' environment. This compares with $34.9 \%$ of dentists who perceived the new system as a 'treadmill' immediately before its implementation. Three hundred and forty-eight (83.4\%) disagreed that they were able to spend more time on prevention and $356(85.3 \%)$ did not feel they had more time to spend with patients - key objectives of the reforms. Two hundred and seventy-five (65.9\%) respondents agreed that local NHS commissioners were controlling their business. Conclusion This survey, conducted 18 months after the implementation of the new commissioning arrangements, suggests that practitioners are deeply unhappy with local commissioning. It raises questions as to whether the changes have achieved the Government's stated objectives in reforming state-funded primary dental care.
\end{abstract}

\section{EDITOR'S SUMMARY}

There is a human tendency to want to say 'I told you so' when something that we have predicted will happen actually comes to pass, especially when it has been instigated or implemented against what we feel is better judgment. Consequently, the reaction to the results of this survey of GDPs in Wales pre- and post-introduction of the new NHS dental contract might well attract such a response from the profession.

However, such a reaction while providing perhaps some measure of selfsatisfaction is not really the one that we might have preferred from the viewpoint of improved service to patients and working conditions for the practitioners involved and their teams. This being especially the case since they were explicit objectives for the introduction of the contract. The results might have been different; that is why we undertake research, to test what we think might be true and provide the evidence to support it. Yet from the anecdotal evidence given by GDPs in Wales and in England, the hypothesis seemed a fairly safe one.

The findings are also in line with other research we have published recently regarding the factors from which dentists derive job satisfaction. These are not primarily to do with remuneration but focus a lot on self-determination, in this survey represented by questions such as 'flexible working hours' and 'being my own boss'. They are perhaps best represented on the large scale by the use of 'treadmill' to describe what the contract was supposed to end, but which respondents clearly felt it had not. With the work of the independent review of NHS dentistry being undertaken by Professor Jimmy Steele (see page 455) still in progress, one would hope that the findings of this paper will be fed into the process of consideration of evidence and will inform the subsequent recommendations. The evidence-base of this paper is very strong and in an era in which so much emphasis is placed on such validation this is both a timely and very valuable piece of research.

The full paper can be accessed from the $B D J$ website (www.bdj.co.uk), under 'Research' in the table of contents for Volume 206 issue 9.

Stephen Hancocks, Editor-in-Chief

DOI: 10.1038/sj.bdj.2009.393 


\section{TO ACCESS THE BDJ WEBSITE TO READ THE FULL PAPER:}

- BDA members should go to www.bda.org

- Do not login on the BDA home page, if you are already logged in, please log out.

- Then, in www.bda.org click on the link to the BDJ in the top left of the screen. A new window will open. If a new window fails to open please check the settings of any pop up blocker software that you have installed on your computer.

- You will now be asked to login with your BDA website login details which are on your BDA membership card.

- Once your details have been entered you will be transferred to the BDJ website. If your login does not work please contact the BDA Membership Department on 02075634550.

- If you are not able to access the article on the BDJ website there may be an issue with your system's firewall. If so, return to the BDA homepage and click on the link 'BDJ access problems' and follow the step by step guide.

\section{COMMENT}

Many words have been written about the new contract and how it has affected dentists and patients in England but there has been little information dealing with the situation in the smaller population of Wales, which was also subject to the changes.

This paper addresses the attitudes of dentists in Wales by looking at the attitudes of the dentists before the introduction of the new contract and then reassessing their attitudes some 18 months after the start of the contract in light of their actual experience of working in the system.

Wales has about 608 NHS dentists, all of whom were sent a questionnaire and 417 of whom responded. The questions asked varied in range from the straightforward factual to the perceptions and 'feel' that dentists had in relation to the 'old' contract and the 'new'.

Most dentists believed the old contract to be a 'treadmill' which meant that they had to produce more and more work to stand still financially. In consequence they were happy to agree that change was necessary. But have they welcomed the new contract and do they feel that the current arrangements are better for them? This is something the paper tries to answer.

It will come as no surprise that the changes were viewed with apprehension prior to their introduction as we dentists tend to be quite conservative in our attitudes and regard all change as a major disruption to our lives. But the aspects which make this paper most interesting are the responses to the questionnaire that was sent out some 18 months into the new contract, to see whether the stated intentions of the dentists at the inception of the new contract materialised into actuality or were abandoned when the new working arrangements were tried and tested in use.

What objections to the new contract terms have emerged from the survey that are different from the original perceptions, or are dentists' worst fears being realised? This paper makes an interesting read.

\section{Ellman, General Dental Practitioner}

\section{AUTHOR QUESTIONS AND ANSWERS}

1. Why did you undertake this research? The introduction of the new contact in April 2006 is arguably the greatest change in the commissioning of NHS primary dental care services since the inception of the NHS. Stories and anecdotes about dental services have become common place in the media over recent years. We felt it important that formal investigation of the impact of the contract was undertaken. As a follow-up to a previous survey, this work allowed us to examine the extent to which the contract lived up to (or did not live up to) the expectations of general dental practitioners, as expressed in the period immediately before the contract was introduced. This study forms part of a larger body of work that we undertook on behalf of the local health boards in Wales, in which we also examined the impact of the contract on vocational trainees and on the public.

\section{What would you like to do next in this} area to follow on from this work?

As local contracting evolves there is a need for health authorities to be able to plan and commission dental care in a more effective manner than is currently the case. We are currently working on systems to allow modelling of dental care to permit more sophisticated contracting. 